\title{
Bibliotherapy in practice: a person-centred approach to using books for mental health and dementia in the community
}

\section{Abstract}

Bibliotherapy is the use of texts to provide support for people with mental and physical health problems. It is widely seen to have beneficial outcomes but there is still disagreement about how best to deliver bibliotherapy in practice. This article explores one method of delivering bibliotherapy which has evolved over the past 20 years in the north of England, the Kirklees approach. Using a multi-method qualitative research design including reflective observations, interviews and document analysis, the article examines how bibliotherapy has been delivered to people with mental health problems and dementia in a volunteer-led scheme. As an inherently flexible and adaptable approach, bibliotherapy in practice in Kirklees is best defined by its ethos, rather than a prescriptive list of its activities, as is the case for many alternative approaches to bibliotherapy. It is an approach to bibliotherapy which: is person-centred; avoids value judgements of texts and responses to them; is often co-produced with group participants; is about making a contribution (in a variety of ways); emphasises social connection. This separates it from other current models of bibliotherapy operating in the UK, and demonstrates how it may be tailored to the requirements of those experiencing diverse mental and physical health conditions. A more responsive form of bibliotherapy, as outlined here, has the potential to provide support across the community. 


\title{
Bibliotherapy in practice: a person- centred approach to using books for mental health and dementia in the community
}

\author{
Introduction
}

Bibliotherapy is a widely-used intervention, which aims to help people with mental health conditions to access texts that will support them and provide insight, guidance or reassurance. Though widely used, it is not well defined: the texts used in different bibliotherapy contexts vary, and include self-help materials, fiction and poetry. Approaches to selecting the texts are also diverse: often self-help materials are selected by clinically-trained professionals with a background in psychiatry, and lists of suitable fiction and poetry are available from scholars of English literature, librarians and readers themselves. Bibliotherapy is delivered in groups or with individuals on a one-to-one basis, and approaches to working with texts are also wide-ranging.

This means that although bibliotherapy is spoken of as if it is one thing, in practice, it is not, and although the general premise - that solace can be found in books - is broadly agreed, highquality evidence of effectiveness of different models and delivery in practice is still limited. ${ }^{1}$ This article explores bibliotherapy in one context: the West Yorkshire community of Kirklees. Kirklees, a metropolitan borough in the north of England, has a 20 year history of using bibliotherapy with people in the community, though how this has been implemented has varied over this time period. This article focuses primarily on current activity which caters for individuals with mental health conditions or dementia. Evaluation work has previously captured important aspects of how bibliotherapy schemes operate in Kirklees; this article investigates what makes this approach to bibliotherapy different to other models, with the aim of providing insights for others undertaking bibliotherapy, or those interested in thinking about the therapeutic value of books and reading.

\section{Bibliotherapy: current practices}

Bibliotherapy is the use of books to help people to improve their mental health and well-being. ${ }^{2}$ These texts can be informational, educational, or imaginative literature, e.g. fiction and poetry. Bibliotherapy has a long and international history, which is well documented elsewhere. ${ }^{3}$ The approach to bibliotherapy varies depending on the type of text used. Since 2001, many UK public libraries have operated programmes offering self-help type resources to connect readers with information about mental health conditions. ${ }^{4}$ Much previous research on bibliotherapy 
focuses on establishing the effectiveness of these resources on symptoms of diagnosable mental health or physical health problems. This widely-used model is popular because it is simple to deliver. Readers can be recommended titles via their GP or can self-refer and access texts recommended by mental health professionals, which often deliver a form of cognitivebehavioural therapy (CBT)-based support for diagnosed mental health conditions.

Schemes working with fiction and poetry are becoming increasingly common, though still not delivered at scale across the UK. Often these schemes work with groups of people rather than an individual reader. As interest has increased, there has been some evaluation of the effectiveness of these initiatives, though this has often been conducted by those closely involved (and therefore invested) in the schemes. ${ }^{5}$ Previous research has established that reading has the potential to be relaxing, transportive and escapist. ${ }^{6}$ It can also facilitate an emotional connection between reader and text. ${ }^{7}$ In a group setting, the relationship between the group members also has a role to play in establishing therapeutic outcomes. ${ }^{8}$ Increased confidence and social inclusion have also been reported as outcomes. ${ }^{9}$

One approach, led by The Reader organisation in Liverpool, has a specific 'Shared Reading' model that works with people to increase their appreciation of classic fiction and poetry. This has spread throughout the world (including Australia, Scandinavia and North America), and its popularity is important to acknowledge. Originally working with people with mental health problems, they now also work with people with dementia. ${ }^{10}$ The Reader predominantly use literary work that they refer to as 'great literature', for instance George Eliot, Doris Lessing, Jane Austin, William Shakespeare and Charles Dickens. ${ }^{11}$ With its basis in English and education, The Reader place value judgements on fiction and poetry with which not all may agree, and which represents an important difference from the Kirklees approach described below.

As most bibliotherapy activities focus on the use of written text, whether in the form of novels, poetry or self-help books, research into the use of alternative forms of 'text' is limited. In recent years, however, there has been a growing interest in the use of graphic novels and comics as a mode of bibliotherapy. Research has shown that comics can provide a sense of companionship, reassurance and recognition through the realisation that others are dealing with the same issues, making the format potentially valuable as a bibliotherapy resource. ${ }^{12} \mathrm{~A}$ further development in recent years is the growing use of technological solutions to support the delivery of bibliotherapy. ${ }^{13}$

Most commonly, bibliotherapy schemes are designed to support people with mental health problems. Some groups are designed exclusively for individuals who are receiving medical/healthcare support for mental health conditions, for example on psychiatric wards ${ }^{14}$ or in other health care settings. ${ }^{15}$ In other cases, bibliotherapy groups take place in a community setting and may include people with a diagnosed mental health condition, but also those without a medical diagnosis (or who do not wish to disclose a diagnosis), or who are experiencing more general wellbeing-related concerns. ${ }^{16}$ 
In recent years, there has been increasing awareness of the value of creative arts practice in dementia, ${ }^{17}$ and as a result, growing interest in expanding bibliotherapy services to engage with people living with dementia. The Book Well Program in Australia is based on The Reader's Shared Reading model. The concept of Book Well groups has been adapted for people with dementia by including shorter, stand-alone texts and poetry chosen to assist with dementiarelated issues. The texts are usually printed in larger font to allow participants to read along and the facilitator speaks more slowly and loudly, taking time to describe pieces in the story that need explanation. The sessions for groups catering for people with dementia are usually shorter than other sessions. An evaluation of this programme in 2010 found that reading aloud could have positive wellbeing effects as well as improving communication and recall. ${ }^{18} \mathrm{~A}$ further evaluation in 2012 found that the programme had a positive effect on participants by offering an improved type of social activity where they could connect with each other in different ways and provided positive mental health benefits. ${ }^{19}$

Genuis $^{20}$ conducted research into a read-aloud bibliotherapy group for elderly people, including some with dementia in British Columbia, Canada. She found cognitive benefits of participation for people with dementia as they conveyed that they understood the meaning of passages read aloud and expressed that they were reminded of previously forgotten memories.

These examples show that approaches to bibliotherapy are diverse, and vary in style for people living with mental health problems or dementia. As a complex intervention with many variables, ${ }^{21}$ establishing effectiveness of bibliotherapy is difficult, but there is some evidence that suggests that bibliotherapy has a positive impact on those who engage with this practice. ${ }^{22}$ However, most current approaches to bibliotherapy take the text, or addressing the symptoms of a mental health problem, as the starting point for considering the relationship between the text and the reader. Here, we explore a different approach to bibliotherapy which takes a more person-centred focus to connecting readers and texts.

\section{Bibliotherapy in Kirklees}

Bibliotherapy schemes began operating in Kirklees and, initially in Calderdale (a neighbouring borough, though this was short-lived) in 2000, with the appointment of three part-time dedicated bibliotherapists employed within the public library service. Their backgrounds and previous experience were diverse - social work, education and librarianship - but they all shared a passion for connecting people with texts. These bibliotherapists ran group sessions and one-toone appointments focused around getting people to engage with books, under the banner of RAYS, the 'reading and you scheme'. The three bibliotherapists worked closely together, refining their approach and sharing ideas about what worked in practice; they stopped working with individuals and worked more with groups so that they had a greater impact in the time available.

Over time, there was change in the team as some members retired and others came on board. In 2009, there was an attempt to spread the approach across the UK, with the online publication of the bibliotherapy toolkit, ${ }^{23}$ a short booklet of writing from group participants, and a national 
conference. As part of ongoing efforts to establish an evidence base around bibliotherapy, the bibliotherapists participated in several research and evaluative projects, which aimed to support the continuation of the service. ${ }^{24}$ Kirklees public library service was innovative in being the only public library service in the UK to employ bibliotherapists with a specific remit to deliver group sessions on an ongoing basis; in 2016 this role was dissolved and it became part of Kirklees librarians' outreach work to deliver bibliotherapy sessions. This was predominantly in a sixsession group model, rather than on an ongoing basis.

One of the bibliotherapists previously employed by the public library service took the established materials and ethos, and set up a training company, Words for Wellbeing, which aims to further spread the approach. Around the same time, Third Sector Leaders Kirklees, an organisation which manages a number of volunteer schemes, applied for funding to run a bibliotherapy scheme using fiction, poetry and other creative resources for people with mental health problems and people with dementia, using a volunteer-led model. This funding application was successful, and in 2018, this scheme, Words in Mind, started to offer bibliotherapy sessions in Kirklees.

Words in Mind can be seen to have evolved from this shared history of bibliotherapy across the district and works alongside the library service. The Words in Mind scheme is delivered by volunteers and sessional workers, who are trained to run bibliotherapy groups for people with dementia and/or people with mental health problems around Kirklees. Volunteers and sessional workers are trained by Words for Wellbeing, who deliver introductory training, as well as training accredited to level one of the UK qualifications framework. The Words in Mind project manager also provides training and support to volunteers, including Dementia Friends training.

At time of writing, groups are run in various locations: NHS care settings including an inpatient rehabilitation unit for people with severe mental health problems; community centres; residential care homes; public libraries; in partnership with organisations that support recovery from mental health problems including as part of the Recovery College; and as part of established groups such as a group for people with young onset dementia. All are delivered by one or two facilitators, who lead each group.

This means that the Words in Mind approach is allied to, and draws on, the previous approach to bibliotherapy in Kirklees. Unlike other approaches to bibliotherapy, which emerged from an English literature/ education ethos, or from a healthcare setting, the Kirklees approach takes a more open and diverse stance in response to the question: what is bibliotherapy? The Kirklees approach is markedly different from models such as Shared Reading, for example, which places strong emphasis on the importance of written texts, rarely drawing on visual imagery or song. Instead, the Kirklees approach is more focused on using resources in diverse forms to engage people with words.

This article aims to outline the aspects of the Kirklees approach that differentiate it from other ways of working with fiction and poetry for mental health support and dementia, drawing on data collected as part of a wider evaluation of the Words in Mind scheme, supported by previous research conducted in Kirklees. ${ }^{25}$ This article does not aim to establish the effectiveness of 
bibliotherapy, but by surfacing the underpinning assumptions of the Kirklees approach, we elucidate the ways in which it is enacted in practice, demonstrating how the evolution of this model has led to important insights into bibliotherapy as a relational practice which have not previously been shared or theorised. Recognising this relationality is important is because it is fundamentally overlooked in other theorisations of bibliotherapy, which sometimes focus on 'what the text does' rather than the relationship between text and reader.

\section{Methodology}

The aims of the research, to understand the delivery of bibliotherapy in practice in Kirklees and to theorise its underpinning principles, meant that a multi-method qualitative approach, aligned to an ethnographic methodology was appropriate. Building on the anthropological tradition of long-term immersion in a setting, short-term ethnography ${ }^{26}$ has become an established method of gaining rich data about a setting through observation, description and analysis, ${ }^{27}$ particularly in healthcare settings. ${ }^{28}$ This is partly a pragmatic research design, but one that has the potential to produce important insights into specific phenomena. ${ }^{29}$

\section{Data collection}

Data were collected via reflective observations of the groups, interviews with relevant stakeholders and gathering of relevant materials - brief email reflections, examples of promotional materials for different groups, session plans, lists of resources, plus creative writing produced within groups/ by group members and shared with permission. To orientate ourselves to the implementation of the Kirklees approach, we also attended some group sessions with verbal permission from group facilitators and members, though these were not a formal method of data collection and are not included in the number of observations reported below.

The research was co-designed with volunteers and sessional workers who currently run bibliotherapy groups. In an initial three hour workshop, we discussed what outcomes they had already observed and thought might be valuable to group participants, and the difficulties of quantifying the complex emotional response to the literature used in the groups. This helped to clarify the appropriate methodological approach. At this point, we formally recruited the coresearchers into the study, providing information about involvement and providing the opportunity to opt out. No patients were involved in the design of this research.

Co-researchers were then asked to use an observation template to structure reflections on their experiences of running bibliotherapy groups. Between June 2019 and September 2019, seven volunteers completed twenty-one structured observations of their practice. The number of groups operating fluctuated during this time, as groups started up and others ended, depending on participant numbers and volunteer availability, but on average there were 39 groups (range: 31-47) extant at time of research. This means we were able to capture some longitudinal observation data, with repeated reflections written about a number of groups, and some more 'snapshot' observations of other groups. 
Groups met weekly, fortnightly or monthly, and each group session lasted between one and two hours, in line with the needs of the group; this did not change as part of the research design. Group size varied from 1-2 participants, up to 15 in some sessions; the average was 6-8 people. Reflective observations were completed in an equal mix of groups delivered to people with mental health problems, those delivered to people with dementia, and more general community groups. All participants attend the groups voluntarily. The observation template was completed as soon as possible after the sessions, giving a detailed account, including outcomes for participants and practical challenges of delivering the sessions.

Throughout this three-month process, we worked with the co-researchers to reflect on their experiences of bibliotherapy as a group facilitator. Two further workshops were used to have a mid-point 'check-in' and finally to present remaining questions to co-researchers and share some preliminary themes in the data. This was to allow us to 'sense-check' our preliminary analysis and to clarify whether identified themes resonated with co-researchers. ${ }^{30}$

Alongside the reflective observation process and workshops, we also formally interviewed 15 stakeholders, including management staff from the co-ordinating organisation, sessional workers and volunteers, residential care home activity coordinators, public library staff, community centre managers and mental health organisation support workers. These stakeholders were recruited via the project manager, who identified them as having specific insights into one or more aspects of bibliotherapy in practice (training, delivery, management and co-ordination).

Around half of these interviews took place face-to-face, with seven conducted over the telephone. Interviews lasted 15-45 minutes, with most averaging around 30 minutes and all interviews were audio recorded and fully transcribed. Interviews were conducted using Kvale and Brinkman's ${ }^{31}$ principle of 'interviewing as a social practice', acknowledging the situated and relational nature of data gathered in this manner.

Gathering formal interview data helped to triangulate and add rigour to the structured observation process; asking diverse stakeholders about their experiences working in or alongside the Words in Mind bibliotherapy scheme allowed for some reflection on group members and texts, as well as directly addressing the question of what makes bibliotherapy different from other group activities such as art, creative writing or crafts.

\section{Ethical considerations}

Ethical approval for the research was granted by Lancaster University Faculty of Health and Medicine Research Ethics Committee. Data were managed in line with General Data Protection Regulations (GDPR). All participants gave informed consent to be interviewed. Co-researchers participated in a short training session (in the first workshop), in which we discussed and agreed the principles of ethical research. Structured reflective observations of practice were anonymised and no identifiable information was collected about group members. Information about the research was provided to all groups where a facilitator was conducting observations, 
to give them the opportunity to opt out of having any information at all recorded about their presence in the group. We did not receive any information from co-researchers about group members opting out.

\section{Data analysis}

Analysis was conducted using a data-driven constant comparison approach to foreground experience. ${ }^{32}$ Data were managed using NVivo 12 software and both authors analysed the data independently, before discussing preliminary themes and ideas. The different sources of data (observations, interview transcripts and materials) were also analysed separately, then brought together to identify commonalities and differences, using themes developed from the data and concepts from the literature as a sensitising framework. ${ }^{33}$ As stated, the initial themes were presented to co-researchers to sense-check before the analysis was completed. This enabled us to identify any missing themes that co-researchers thought were important to highlight, and confirmed that the preliminary themes reflected practice. The aim of an ethnographic approach is to go beyond describing and into theorising, and so as part of the analytical process, we focused on identifying the assumptions and broad ethos underpinning the approach to bibliotherapy, aiming to understand not only what was happening, but why.

\section{Findings}

From our rich sources of data, we identified five principles that structure the practices of bibliotherapy in Kirklees. As an inherently flexible and adaptable approach, bibliotherapy in practice in Kirklees is best defined by its ethos, rather than a prescriptive list of its activities. It is an approach to bibliotherapy which: is person-centred; avoids value judgements of texts and responses to them; is often co-produced with group participants; is about making a contribution (in a variety of ways) and emphasises social connection.

\section{Person-centred bibliotherapy}

The Kirklees approach to bibliotherapy is fundamentally diverse and tailored to the needs of participants in each group. The starting point in planning a session is the needs of participants (rather than the literature or other texts which are used). This took various forms in practice: group members could select and bring their own texts and some produced their own writing. Some groups included more discussion, while others make regular use of other media or activities. Finally, some adopted an inclusive and shared approach to reading aloud, while in others the facilitator reads. We describe this as a 'person-centred' approach, drawing on recent understandings of service delivery in health and social care. ${ }^{34}$

Fundamentally, the direction of each bibliotherapy group was shaped by the group members, guided by the group facilitator, and was tailored to their needs and interests. This tailoring made it a diverse and versatile intervention, but ultimately led to questions from external organisations 
involved in the scheme, about what to expect from a bibliotherapy group, as there was no one model to describe. Often, the mental health groups and dementia groups had some differences, with the facilitator taking a more active role in groups where the participants had dementia, but this was not always the case.

The variety of group sessions can be seen as a strength of the Kirklees approach, in that it allows facilitators to meet particular needs and be responsive to the group. This variation of practice was well-established and had been observed in previous incarnations of bibliotherapy in this area. As an interviewee explained:

“We don't like to be prescriptive, because what works for one person might not work for another, and it's dangerous to start making assumptions that if you're working with people who have depression, well, this will work well with them, because they're not a lump of depressed people, they're individuals, who are experiencing their depression in different ways. So I think it's very dangerous to be prescriptive like that." (Interview, 10)

Indeed, there was an awareness that even within one group, the experience could vary week by week depending on the mood of those attending.

"Some weeks, people really want to read Wordsworth and go deep into what it's all about, and other times, people really don't, and they just want to really talk about the old jingles that used to be on the radio 20 years ago!" (Interview, 05)

Responding to group participants' interests and requirements meant that some groups focused on a model of sharing reading aloud, while others relied on the facilitator to read poems and prose aloud. In some groups there was a lot of time given over to sharing of experiences in relation to the resources, while others focused more on the content of the resources shared and left less time for reflection. There was scope to engage with images, sensory resources (things to smell or touch), and reviewing song lyrics (and singing or listening to the song) alongside more traditional poems, short stories and extracts from novels. In some groups, there was a mixture of reading and writing, with participants sharing their own creative writing as well as engaging with resources brought by the group facilitator. In some, this was a strong feature of the group, whereas in other cases it happened on a more occasional basis. This led to a feeling that there was a clear sense of 'ownership' in many of the groups; the group belonged to them and could be shaped by their needs.

\section{Resources and value judgements}

The Kirklees bibliotherapy sessions offered a space where all positive contributions were valued and respected. This had helped many participants to develop in confidence. While the sessions encouraged greater awareness and understanding of literature and culture, this is defined widely and intended to be inclusive, including for people who may not have considered themselves to be readers. The notion of 'text' or 'literature' included a wider range of materials and media than is often the case in bibliotherapy interventions. 
The range of resources, both in terms of type and format, reinforced the flexibility of the Kirklees approach. Facilitators clearly put a great deal of time and effort into the selection of resources for their sessions, and most make use of a wide variety of texts and resources, with session plans showing up to 20 different resources selected to draw on, in response to the needs and mood of the group members. The pace of the session, and the number of resources used, varied considerably from session to session, and was difficult to predict. Facilitators explained that they found a need to take a lot of material, even if, in practice, they only used one poem. Judging when to step in and move the session on, and when to step back and allow people more time to reflect on a text was a key skill for facilitators.

The resources used varied from session to session and group to group, but commonly included 'classic' or well-known books and poems; less widely known texts; 'popular' texts (e.g. funny poems); lyrics; quotes; images; newspaper/magazine articles; local history resources; short stories/ quick reads; and (auto)biographies. Facilitators did not place value judgements on the resources; their use was more about encouraging engagement.

"And there are no right answers to what is good or what everybody should like, and it isn't high culture - although if something's good, then that's fine, people enjoy it - but reading a page of Mills \& Boon - which I have done! - if it's going to get the group talking and engaging and disagreeing, then that is important." (Interview, 03)

As described in greater detail below, no judgements were made about the ways that individuals engaged with the resources: listening, expressing opinions about the resources (positively or negatively), or even simply maintaining eye contact could be equally valid forms of engagement depending on the group or the individual concerned.

Unlike some approaches to bibliotherapy, in Kirklees, there were not prescriptive lists of what resources to use. However, in the current volunteer-led model, there was an awareness that sharing resources could be valuable; as one facilitator commented, "it would be lovely if we had a resource bank" (Interview, 01) to save time curating resources for different themes and groups. These resources would still need to be 'customised' or adapted by individuals to suit the way in which they facilitated sessions. As another facilitator said, "I wouldn't want us all going out with the same packs" (Interview, 02). Importantly, resources were not only provided by the facilitator, but often by group members too.

Furthermore, as a facilitator commented, the fact that a text had not worked well with a particular group did not necessarily mean it would not be appreciated by another group:

"Texts work differently with different groups. It's tempting to go home and think, "They didn't like that poem; I won't read it again". But then it might be loved by a different group." (Reflective observation, 2019-08-29)

Another facilitator emphasised that it was not just down to the text as to how well it was received by a group, it was also in the way it was presented by a facilitator. Texts could be read or performed, as the facilitator encouraged the group to engage with them: "So I can't think of a 
type of book which doesn't work; I think it's how well the thing is written and how well I read it." (Interview, 03)

Many facilitators brought printed copies of some of the texts they intended to read for participants to follow along and take away if they wished. Sessions in care homes, in particular, typically included a range of media, such as images, objects/props, large print/picture books and reminiscence resources. Many of these groups were quite new at the time of the study; as these groups bedded in, facilitators refined their approach to thinking about what worked in terms of both type and amount of material - balancing the need to provide stimulus without being overwhelming and ensuring objects are suitable for the group. There were also attempts to provide diverse resources, for example, reflecting different cultures and genders. In addition, the resources selected for sessions varied in length and complexity. Some facilitators also had a 'fall-back' resource, such as a poetry anthology, which they could use if they needed additional material, or if the session went in a different direction than originally anticipated.

In the case of some of the dementia groups, one interviewee described the care home sessions as being "more hands-on" (Interview, 01) in comparison to community-based or mental health groups. This might mean that the session included games and singing for example, or simple activities like the creation of a 'memory jar.' Facilitators also made use of objects, particularly those that might stimulate a range of senses, for example, flowers to smell, pebbles to touch or fruit to taste. An interviewee explained, "By using different senses, it helps them to engage with the whole experience and to engage with the words, so they're not just hearing them or seeing them on the page" (Interview, 07).

Some sessions also included other activities, for example, quizzes. Although these were more common in the dementia or care home groups, they also took place in the mental health and community groups where, for example, group members might write their own quizzes. As a facilitator pointed out, deciding whether or not to include an activity such as a quiz required a good knowledge of the group.

"Quizzes - love 'em or hate 'em. They are a bit like marmite. I have learned it is about knowing your group. I have tried quizzes at my Words in Mind sessions in care homes and have usually given up after a few questions [...] My library group enjoy quizzes about general knowledge but wouldn't want one every week. So I think it's about knowing your group, encouraging people to write quizzes if they want to and recognises when a quiz is not working and just move on." (Reflective observation, 2019-08-29)

Reflective observations showed that groups often include more general discussions too, for example, books that group members are currently reading. For facilitators, having a theme was seen as helpful as a way of bringing the discussion back on track if it became too tangential, or too intense. However, on other occasions there was an acknowledgement that "you just have to abandon the theme" (Interview, 01) and facilitators responded to the mood of the group instead. 


\section{Co-production}

A further finding, which can be connected to the person-centred ethos of the bibliotherapy groups, was the idea of co-production. Observations and interview data showed that sessions were co-produced between facilitators and participants. In some groups, this was more evident, for example, where facilitators acted more as a group member, sharing their own writing alongside other group members. In addition, participants frequently brought along texts to read at the sessions or helped to devise other activities such as quizzes.

In other groups (particularly those in care homes), co-production was not as obvious; however, co-production could still occur, usually in more spontaneous ways. Amongst people living with dementia, some of the texts, especially poems, might bring a sense of recognition and stimulate memories, for example, remembering poems they had read at school. This recognition and response shaped the direction of the group.

"So I was reading [I Wandered Lonely as a Cloud] and then they just joined in, and I were quite amazed that, from being a group that seemed quite... not too interactive, if you like, they just seemed to come alive, and they were saying the words, and they knew all the words, all the way through, and I were just taken aback by it, and then, from speaking to them, they were the poems that they'd learnt at school." (Interview, 04)

Co-production was evident in the themes which structured the sessions; most sessions had a theme, often chosen by the group themselves. These varied widely including, for example, animals, musicals, books, gardening, sci-fi, happiness, the sea and dance. The skills of the group facilitator were important in selecting the theme; this was evident in one example shared by a support worker at a service for people with mental health needs.

"Sometimes if I have suggested a certain theme and it sounded a little negative, [the group facilitator] has been really good at sort of rephrasing it. We knew that somebody who attended the service quite regularly was coming to an end, and so I was like, "How about we have next week's theme of endings?" and then [name] rephrased it as "Perhaps we could have new beginnings," and I thought that was such a lovely way of doing it, it was such a positive way of reframing it." (Interview, 15)

This shows that the support and training given to the group facilitators was key in structuring this co-production. Observation data showed that this co-production was present outside the sessions too, with participants showing increased interest in, and engagement with, literature and culture more generally, and who, for example, might select texts to bring along to sessions.

"I think all members brought something to the session - from quotes from Sci-fi books and films, to books they are reading at the moment to quizzes. [The co-facilitator] and I took a step back and it feels like it is their group. They have gelled together so well. We have a group of core members who return each week and bring things to read."

(Reflective observation, 2019-08-29) 
In some groups, participants also wrote their own poetry or creative writing and shared it within the group. One facilitator commented that there was evidence that participants: "think about the topic outside of the group and put some time aside each week in order to prepare for the session" (Reflective Observation, 2019-08-05). For many participants, it was the first time they had engaged with literature since school. Nevertheless, the benefits were not limited to group members who had previously engaged with reading and literature; one repeated comment from people who worked alongside the groups was that they had an appeal that transcended expectations.

"You'd be surprised how people enjoy it. I'm surprised myself, for the people who go to it, because I wouldn't have expected them to enjoy it." (Interview, 09)

Enjoyment of the groups, as an outcome, may seem obvious, but this was a key part of two of the following themes, which highlight some of the outcomes for participants in the bibliotherapy groups: making a contribution, and social connection.

\section{Contribution}

The idea of making a contribution, and relating to literature and each other, was central to the Kirklees approach to bibliotherapy. Contribution took many different forms: group members could read parts of a text aloud; bring texts along to the session; contribute to discussions about the text; or support other group members as they shared some insights about the text or their own lives. Participants were able to decide how they wished to contribute, but it was clear that all contributions were valued.

There was a feeling amongst some volunteers that participants in the mental health groups "seem to bring more to the session", for example, bringing their own writing or taking turns to read, whereas in care homes, "they're very happy to listen" (Interview, 01). As another facilitator described, in a care home "it's almost like you're performing" (Interview, 02). At times, this could be difficult as it might appear that participants were not listening or contributing, but several interviewees spoke about how they had been surprised by participants' unexpected responses.

"You've mentioned something and a lady's just put her head up and told you the whole poem because they memorised it at school. And those days are fab and they happen quite a lot." (Interview, 02)

This facilitator also described how her own reactions to someone sleeping during a session had changed and she had come to view this as a positive response: "people will always nod off, because it's relaxing...quite a compliment" (Interview, 02).

A member of staff from a care home explained how 'involvement' might look different for these groups compared to those within a community or healthcare setting: 
"I don't really need to ask them if they enjoyed it, because I know, because if they hadn't, they would have got up and left....nobody's fallen asleep, they've been aware, they've made eye contact, and it's a definite good sign." (Interview, 06)

Furthermore, while participants in the care home groups did not prepare something in advance to contribute to the group, as per some of the community sessions, they still brought their own contributions to the session, for example, by spontaneously singing or reciting, as described above.

In mental health settings, contribution could present some different challenges. For these groups, getting the balance right (particularly not allowing the conversation to get 'too dark') was a key issue. However, interviewees acknowledged that the groups needed to offer a space for people to discuss difficult experiences.

"There's something about that kind of experience as being more universal than you would think they were, and poetry giving people a chance to say, "Oh, no, actually, me, too, that happened to me". So I think it gives people room to talk about difficult experiences." (Interview, 05)

Importantly, there was a feeling of equality of contribution within some groups. As the current incarnation of the Kirklees approach was volunteer-led, some volunteers with lived experience of mental health issues identified this as a benefit for themselves as well as for group members.

“You're just one of the people who's facilitating: you're just one of the members of the group, and I think you can bring things along and you can share things that people haven't heard before and they can evaluate. You can listen to what people have got to offer and learn so much as well. I think as a facilitator for the groups, you get as much, if not more, than the people that attend, I think, genuinely. When you've had a really good session, for me, I come away and I feel really uplifted." (interview, 04)

A benefit of the bibliotherapy groups for many participants, connected to this idea of being able to contribute, was increased confidence. For some, this might be confidence to read aloud, especially for people with health conditions that might mean this was challenging. In groups where participants shared their own writing, again, this was a contribution that was seen as a beneficial outcome for many, who grew in confidence as they felt more able to share short pieces of writing and express their thoughts in a format they previously might not have felt able to engage with.

\section{Social connection}

For many involved, the bibliotherapy groups offered a vital opportunity for social interaction and connection. In many cases, this connection extended beyond the sessions themselves.

Crucially, being part of a bibliotherapy group was seen to allow people to make a "connection to other people in a way that goes a bit deeper than just a general chat" (Interview 14). Through 
engagement with literature, participants made connections not only to the texts read, but to each other as their shared their reactions and their own experiences.

One of the most obvious social benefits was increased opportunities to interact with other people, especially for participants lacked opportunities to do so at other times of the week. The sessions provided a safe space for people where they felt relaxed, comfortable and respected. An interviewee described the bibliotherapy sessions as a place where "you're treated as a human being with value and that you're cared about, and that whatever you're feeling are important and worth sharing with people" (Interview, 05). Participants in many of the groups had become friends and supported each other in numerous ways outside the sessions as well as within them.

When asked about the differences between bibliotherapy and other creative activities, several interviewees highlighted the potential the sessions offered for more in depth conversations. Through literature, participants were able to reflect on their own lives in different ways; "when we talk about the lyrics to a song or the words to a poem, people can share how they're feeling and why it was important" (Interview, 14). Participants identified with characters or emotions, but also found ways to express themselves through literature; "it's almost like people have got those words for you when you couldn't find them" (Interview, 01). Another interviewee pointed out that literature could offer participants a means of talking about how they were feeling, but with a degree of distance.

"They may be more inclined to talk about an issue, maybe that a character's going through in a book or in a story, or a feeling that's expressed in a poem, that they can talk about that almost in the third person in an abstract way, and then it's hoping that that connects with something that they feel, and that they start to feel better or have a greater understanding, maybe, of something that they're going through." (Interview, 12)

In one community centre, which offered many different creative activities, bibliotherapy was seen as valued as it facilitated longer-term social connections as well as engagement with resources.

"But for people to come together and do the group thing, and share experiences as well, and what I can see, as well, is it's people who don't necessarily sit together and chat: you've got different people who are sitting together and chatting, so they're getting these little friendships which you wouldn't necessarily see, because they don't really sit together." (Interview, 09)

This social connection was seen as something that extended beyond the immediate reach of the groups.

Within the dementia groups too, social impacts could be seen, as participants appeared to recall the emotion of a session, if not specific details, for example, by remaining less agitated afterwards or being pleased to see the facilitator again. Unlike some interventions, the dementia groups were not simply about making connections with the past; the main outcomes for 
participants were usually described in terms of conversation and promoting social interaction through connections made with the various texts. By moving the focus away from reminiscence (which can bring its own stresses for those with memory problems), the bibliotherapy sessions presented the opportunity to learn something new in a social setting.

"And they've got an interest in learning new things: just because they're of an age, they don't need to just sit in a chair; they're all up for learning new things." (Interview, 06)

\section{Discussion}

Using a qualitative, ethnographically-informed method to investigate current practices and underpinning principles of bibliotherapy in Kirklees has demonstrated the differences between its ethos and other bibliotherapy schemes. By focusing on this ethos, we have started to explore how bibliotherapy as a relational practice may be person-centred, while still using texts and other resources to engage people with words. By taking a broad construction of what suitable resources and materials might be used, this approach to bibliotherapy avoids making value judgements of texts and responses to them, leading to high levels of co-production with group participants. It empowers them to make a contribution and emphasises social connection.

A person-centred approach focuses on a person's uniqueness and preferences, instead of the particular health condition they may experience, and its expected symptoms and challenges. ${ }^{35}$ It emphasises how there is much more to a person than just their diagnosis, and is a key element of medical practice. However, it is difficult to define as a set of activities and instead the focus is often on the principles that should be observed as part of delivery of care and interventions. The Kirklees approach to bibliotherapy aligns to several of these principles, namely in its compassionate and respectful approach, emphasis on personalisation, and by enabling group participants to develop their abilities. ${ }^{36}$ In some ways, this is not new; as far back as the 1940 s, Estelle Brodman commented, "patients' librarians...should study not books, but people." ${ }^{7}$ In the intervening years, however, many schemes and approaches appear to have placed more emphasis on the importance of the texts used than the people reading them. ${ }^{38}$ Even the oftrepeated phrase 'the right book to the right person at the right time' demonstrates how often considerations about the text come before considerations of the audience. Here, we have outlined how the Kirklees approach has developed and started to re-address this balance.

Similarly, more recent incarnations of bibliotherapy (both self-help and using fiction and poetry) have taken what could be seen as a less inclusive approach by making stringent judgements about what materials are appropriate for use in bibliotherapy. For example, research into a literature-based intervention for older people living with dementia only refers briefly to the use of non-word based resources, and there is a strong sense that these are seen as inferior to wordbased resources, being described as "an extra stimulus for group members that would help them re-engage" rather than being of value as texts in their own right. ${ }^{39}$ Again, the Kirklees ethos differs here, adopting a more open and multisensory approach to the selection of appropriate bibliotherapy materials. 
As a form of co-production, the Words in Mind groups explored here deliberately draw on the assets and capacities of both participants and facilitators to co-construct sessions in a variety of ways, sometimes by collectively planning or preparing, but also spontaneously within the session itself. In some respects, making a contribution might be seen as a weaker form of coproduction. However, in the Kirklees context the notion of contributing emphasises the importance of respecting and valuing all contributions, regardless of whether they conform to more traditional ideas of co-production, or even participation. This is important as not all participants may wish too, or be able to, make the level of commitment required for coproduction, but may wish to contribute in other ways. For example, research into a literaturebased intervention for older people living with dementia notes, "people do not necessarily have to contribute to a discussion to be actively engaging." ${ }^{40}$ Indeed, for participants in both dementia and mental health groups in Kirklees, simply listening to each other could be equally important.

Previous research into bibliotherapy conducted in the group setting has emphasised that the social aspects are very important to group participants. ${ }^{41}$ In particular, Brewster's work on emergent types of bibliotherapy highlights how the relationship between group members, facilitator and text can be used to avoid or engage with emotions. ${ }^{42}$ In the Kirklees approach, the social element of being able to share experiences was similarly important. Again, the responsive and person-centred approach facilitated this in practice, allowing people who had previously not connected to recognise, communicate and become involved in the group environment.

\section{Strengths and Limitations}

By drawing on reflective observations of groups, interviews and examining relevant materials we were able to understand both the implementation of the Kirklees approach, and explore its underpinning principles. This gave us a robust data set to analyse in order to surface the underpinning assumptions of the Kirklees approach.

This article did not aim to establish the effectiveness of this approach to bibliotherapy, but this could be considered a limitation of the research design. However, by generating understanding of the framework that supports this approach to bibliotherapy there is scope for future research exploring the contribution of the elements explicated here. By engaging with established groups, and with organisations who were already supporting bibliotherapy groups, we have accessed a sample of those who support the use of bibliotherapy in practice. Those who do not find bibliotherapy to be helpful will not attend the groups, and therefore their experiences are not represented. Using observational methods (as opposed to experimental ones) to explore bibliotherapy is always liable to encounter this shortcoming in understanding effectiveness.

Some data presented here are also taken from a self-selecting sample of those who were willing to participate in interviews. This group may not be representative of the views of other stakeholders. One further limitation of the research was that due to the practical limitations of 
the research project, we did not interview group participants. Future research should aim to ensure that these participants are included.

\section{Conclusion}

The strengths of the Kirklees approach to bibliotherapy are that it is adaptable to different groups and individuals and potentially has wider reach than other forms of bibliotherapy because of this adaptability. Its adaptability may also be a shortcoming of the approach; trying to communicate and spread an approach based on an ethos and set of values rather than a firm list of resources or model of activities means that enlisting others in the Kirklees approach is challenging. By focusing first on the people who are part of the groups, and starting from their needs rather than starting with texts and resources, the Kirklees approach adds to knowledge around what is important in the relationship between books and reading. Its person-centred principles appears to be positively received and beneficial to people with dementia and people with mental health problems across the region.

\section{Notes}

\footnotetext{
${ }^{1}$ E.T Troscianko, "Fiction-Reading for Good or III: Eating Disorders, Interpretation and the Case for Creative Bibliotherapy Research," Medical Humanities 44 (2018): 201-11.

2 S McNicol and L Brewster, Bibliotherapy (London: Facet Publishing, 2018).

${ }^{3}$ L Brewster, "Bibliotherapy: A Critical History," in Bibliotherapy, ed. S McNicol and L. Brewster (London: Facet, 2018).

${ }^{4}$ L Brewster, "Books on Prescription: Bibliotherapy in the United Kingdom," Journal of Hospital Librarianship 9, no. 4 (2009): 399-407, https://doi.org/10.1080/15323260903253456; N Frude, "Bibliotherapy as a Means of Delivering Psychological Therapy," Clinical Psychology 39 (2004): 8-10. ${ }^{5}$ D Hicks et al., "Public Library Activity in the Areas of Health and Well-Being: Final Report," ed. Museums Libraries and Archives Council (London, 2010), http://research.mla.gov.uk/evidence/viewpublication.php?dm=nrm\&pubid=1068; J Davis et al., "Step into the World of Books: Final Report of the Get Into Reading Project 2004-5" (Liverpool: University of Liverpool, 2005).

6 J Billington et al., "An Investigation into the Therapeutic Benefits in Relation to Depression and WellBeing," ed. University of Liverpool and Liverpool Primary Care Trust (Liverpool, 2010), http://thereader.org.uk/get-into-reading/research/; L. Brewster, "Murder by the Book: Using Crime Fiction as a Bibliotherapeutic Resource," Medical Humanities 43, no. 1 (2017), https://doi.org/10.1136/medhum2016-011069.

${ }^{7}$ L M Rosenblatt, Literature as Exploration (London: Heinemann, 1938); L J Cohen, "Bibliotherapy: The Experience of Therapeutic Reading from the Perspective of the Adult Reader," School of Education, Health, Nursing and Arts Professions (New York: University of New York, 1992).

${ }^{8}$ Dowrick, C, et al., "Get into Reading as an Intervention for Common Mental Health Problems: Exploring Catalysts for Change." Medical Humanities 38, no. 1 (2012). https://doi.org/10.1136/medhum-2011010083.; Longden, E et al., "Shared Reading: Assessing the Intrinsic Value of a Literature-Based Health Intervention." Medical Humanities, June 12, 2015, 1-8. https://doi.org/10.1136/medhum-2015-010704; rewster, EA "'Medicine for the Soul' Bibliotherapy and the Public Library"; Brewster, "An Investigation of Experiences of Reading for Mental Health and Well-Being and Their Relation to Models of Bibliotherapy." ${ }^{9} \mathrm{~K}$ Morral, "Well into Words: An Evaluation of the Kirklees Bibliotherapy Project," 2016, http://media.wix.com/ugd/6b65c6_f430a267c13848bdbe55ae13aa52ecdf.pdf.
} 
${ }^{10}$ Centre for research into reading information and linguistic systems, "A Literature-Based Intervention for Older People Living with Dementia," 2012.

11 Dowrick et al., "Get into Reading as an Intervention for Common Mental Health Problems: Exploring Catalysts for Change."

12 S McNicol, "Bibliotherapy and Graphic Medicine," in Bibliotherapy, ed. S McNicol and L Brewster (London: Facet, 2018).

${ }^{13}$ P McAllister et al., "Towards Chatbots to Support Bibliotherapy Preparation and Delivery," in Chatbot Research and Design. CONVERSATIONS 2019. Lecture Notes in Computer Science, ed. Asbjørn Følstad et al. (Cham: Springer International Publishing, 2020), 127-42.

14 D Chamberlain, "Developing a Reading Group Service for an Older Adult Functional Psychiatric InPatient Ward," in Bibliotherapy, ed. S McNicol and L Brewster (London: Facet, 2018).

${ }^{15} \mathrm{C}$. Deberti Martins, "Bibliotherapy in Uruguay :A Care Study of the Mario Benedetti Library for Patients Dealing with Substance Abuse," in Bibliotherapy, ed. S McNicol and L Brewster (London: Facet, 2018).

${ }^{16} \mathrm{~F}$ Bailey, "Long-Term Impacts of Bibliotherapy Groups: Reading and Writing Together," in Bibliotherapy, ed. S. McNicol and L. Brewster (London: Facet, 2018).

17 Social Care Institute for Excellence, "Creative Arts for People with Dementia," 2015, https://www.scie.org.uk/dementia/living-with-dementia/keeping-active/creative-arts.asp.

18 S McLaine, "Bibliotherapy: Reading for Wellbeing in Old Age," in Alzheimer's Australia Dementia Forum (Melbourne, 2012), https://www.dementia.org.au/sites/default/files/Susan_McLaine.pdf.

${ }^{19}$ McLaine.

${ }^{20} \mathrm{~K}$ Genuis, "Read-Aloud Group Bibliotherapy for the Elderly: An Exploration of Cognitive and Social Transformation," Journal of Applied Arts \& Health 6, no. 1 (2015): 77-89, https://doi.org/10.1386/jaah.6.1.77_1.

${ }^{21} \mathrm{M}$ Campbell et al., "Framework for Design and Evaluation of Complex Interventions to Improve Health," BMJ (Clinical Research Ed.) 321, no. 7262 (September 16, 2000): 694-96.

${ }^{22}$ Morral, "Well into Words: An Evaluation of the Kirklees Bibliotherapy Project"; Longden et al., "Shared Reading: Assessing the Intrinsic Value of a Literature-Based Health Intervention."; Billington et al., "An Investigation into the Therapeutic Benefits in Relation to Depression and Well-Being."

23 J Duffy et al., "Bibliotherapy Toolkit," ed. Kirklees Council (Huddersfield, 2009).

${ }^{24}$ E A Brewster, "Medicine for the Soul' Bibliotherapy and the Public Library," Department of Information Studies (Sheffield: University of Sheffield, 2007), http://dagda.shef.ac.uk/dissertations/2006-

07/External/Brewster_Elizabeth_MALib.pdf; Brewster, "An Investigation of Experiences of Reading for Mental Health and Well-Being and Their Relation to Models of Bibliotherapy."; Morral, "Well into Words: An Evaluation of the Kirklees Bibliotherapy Project."

${ }^{25}$ Brewster, EA "'Medicine for the Soul' Bibliotherapy and the Public Library"; Brewster, "An Investigation of Experiences of Reading for Mental Health and Well-Being and Their Relation to Models of Bibliotherapy."

${ }^{26}$ S Pink and J Morgan, "Short-Term Ethnography: Intense Routes to Knowing," Symbolic Interaction 36, no. 3 (2013): 351-61, https://doi.org/10.1002/symb.66.

27 M Dixon-Woods, "What Can Ethnography Do for Quality and Safety in Health Care?," Quality and Safety in Health Care 12, no. 5 (2003): 326-27.

${ }^{28} \mathrm{~N}$ Armstrong, C Cupit, and N Mackintosh, "Using Ethnography to Study Improving Healthcare: Reflections on the 'ethnographic' Label," BMJ Qual Saf 0, no. February (2018): 1-3, https://doi.org/10.1136/.

${ }^{29}$ N. Armstrong et al., "Taking the Heat or Taking the Temperature? A Qualitative Study of a Large-Scale Exercise in Seeking to Measure for Improvement, Not Blame," Social Science and Medicine 198 (2018), https://doi.org/10.1016/j.socscimed.2017.12.033.

30 GA. Bowen, "Grounded Theory and Sensitizing Concepts," International Journal of Qualitative Methods 5, no. 3 (2006): 12-23, https://doi.org/10.1177/160940690600500304.

31 S Kvale and S Brinkmann, InterViews: Learning the Craft of Qualitative Research Interviewing [2nd Edition] (London: Sage, 2009).

32 K Charmaz, Constructing Grounded Theory: A Practical Guide through Qualitative Analysis (London: Sage Publication, 2006).

${ }^{33}$ Bowen, "Grounded Theory and Sensitizing Concepts." 
${ }^{34} \mathrm{~N}$ Mead and P Bower, "Patient-Centredness: A Conceptual Framework and Review of the Empirical Literature.," Social Science \& Medicine (1982) 51, no. 7 (October 2000): 1087-1110, http://www.ncbi.nlm.nih.gov/pubmed/11005395.

35 T Kitwood, Dementia Reconsidered: The Person Comes First (Buckingham: Open University Press, 1997).

36 The Health Foundation, "Person-Centred Care Made Simple What Everyone Should Know about Person-Centred Care," 2016.

37 Brodman (1942) quoted in J.C Hynes, "Library Work with Brain Damaged Patients: A New Mode of Bibliotherapy," Bulletin of the Medical Library Association 60, no. 2 (1972): 333-39.

$38 \mathrm{~S}$ Hornby and B Glass, eds., Reader Development in Practice: Bringing Literature to Readers (London: Facet, 2008).

${ }^{39}$ Centre for research into reading information and linguistic systems, "A Literature-Based Intervention for Older People Living with Dementia."

40 Centre for research into reading information and linguistic systems.

41 S Hodge, J Robinson, and P Davis, "Reading between the Lines: The Experiences of Taking Part in a Community Reading Project," Medical Humanities 33 (2007): 100-104,

https://doi.org/10.1136/jmh.2006.000256; Brewster, "An Investigation of Experiences of Reading for Mental Health and Well-Being and Their Relation to Models of Bibliotherapy."

42 E A Brewster, "An Investigation of Experiences of Reading for Mental Health and Well-Being and Their Relation to Models of Bibliotherapy," Information School (Sheffield: University of Sheffield, 2011).

\section{Bibliography}

Armstrong, N., L. Brewster, C. Tarrant, R. Dixon, J. Willars, M. Power, and M. Dixon-Woods. "Taking the Heat or Taking the Temperature? A Qualitative Study of a Large-Scale Exercise in Seeking to Measure for Improvement, Not Blame." Social Science and Medicine 198 (2018). https://doi.org/10.1016/j.socscimed.2017.12.033.

Armstrong, N, C Cupit, and N Mackintosh. "Using Ethnography to Study Improving Healthcare: Reflections on the 'ethnographic' Label." BMJ Qual Saf 0, no. February (2018): 1-3. https://doi.org/10.1136/.

Bailey, F. "Long-Term Impacts of Bibliotherapy Groups: Reading and Writing Together." In Bibliotherapy, edited by S. McNicol and L. Brewster. London: Facet, 2018.

Billington, J, C Dowrick, A Hamer, J Robinson, and C Williams. "An Investigation into the Therapeutic Benefits in Relation to Depression and Well-Being." Edited by University of Liverpool and Liverpool Primary Care Trust. Liverpool, 2010. http://thereader.org.uk/getinto-reading/research/.

Bowen, GA. "Grounded Theory and Sensitizing Concepts." International Journal of Qualitative Methods 5, no. 3 (2006): 12-23. https://doi.org/10.1177/160940690600500304.

Brewster, E A. "An Investigation of Experiences of Reading for Mental Health and Well-Being and Their Relation to Models of Bibliotherapy." PhD, Information School. University of Sheffield, 2011. http://etheses.whiterose.ac.uk/2006/.

_. "'Medicine for the Soul' Bibliotherapy and the Public Library." Department of Information Studies. Sheffield: University of Sheffield, 2007. http://dagda.shef.ac.uk/dissertations/200607/External/Brewster_Elizabeth MALib.pdf.

Brewster, L. "Murder by the Book: Using Crime Fiction as a Bibliotherapeutic Resource." Medical Humanities 43, no. 1 (2017). https://doi.org/10.1136/medhum-2016-011069.

_ "Bibliotherapy: A Critical History." In Bibliotherapy, edited by S McNicol and L. Brewster. London: Facet, 2018.

_. "Books on Prescription: Bibliotherapy in the United Kingdom." Journal of Hospital Librarianship 9, no. 4 (2009): 399-407. https://doi.org/10.1080/15323260903253456. 
Campbell, M, R Fitzpatrick, A Haines, A L Kinmonth, P Sandercock, D Spiegelhalter, and P Tyrer. "Framework for Design and Evaluation of Complex Interventions to Improve Health." BMJ (Clinical Research Ed.) 321, no. 7262 (September 16, 2000): 694-96.

Centre for research into reading information and linguistic systems. "A Literature-Based Intervention for Older People Living with Dementia," 2012.

Chamberlain, D. "Developing a Reading Group Service for an Older Adult Functional Psychiatric In-Patient Ward." In Bibliotherapy, edited by S McNicol and L Brewster. London: Facet, 2018.

Charmaz, K. Constructing Grounded Theory: A Practical Guide through Qualitative Analysis. London: Sage Publication, 2006.

Cohen, L J. "Bibliotherapy: The Experience of Therapeutic Reading from the Perspective of the Adult Reader." School of Education, Health, Nursing and Arts Professions. New York: University of New York, 1992.

Davis, J, A Macmillan, G Mair, K McDonnell, and M Weston. "Step into the World of Books: Final Report of the Get Into Reading Project 2004-5." Liverpool: University of Liverpool, 2005.

Deberti Martins, C. "Bibliotherapy in Uruguay :A Care Study of the Mario Benedetti Library for Patients Dealing with Substance Abuse." In Bibliotherapy, edited by S McNicol and L Brewster. London: Facet, 2018.

Dixon-Woods, M. "What Can Ethnography Do for Quality and Safety in Health Care?" Quality and Safety in Health Care 12, no. 5 (2003): 326-27.

Dowrick, C, J Billington, J Robinson, A Hamer, and C Williams. "Get into Reading as an Intervention for Common Mental Health Problems: Exploring Catalysts for Change." Medical Humanities 38, no. 1 (2012). https://doi.org/10.1136/medhum-2011-010083.

Duffy, J, J Haslam, L Holl, and J Walker. "Bibliotherapy Toolkit." Edited by Kirklees Council. Huddersfield, 2009.

Frude, N. "Bibliotherapy as a Means of Delivering Psychological Therapy." Clinical Psychology 39 (2004): 8-10.

Genuis, K. "Read-Aloud Group Bibliotherapy for the Elderly: An Exploration of Cognitive and Social Transformation." Journal of Applied Arts \& Health 6, no. 1 (2015): 77-89. https://doi.org/10.1386/jaah.6.1.77_1.

Hicks, D, C Creaser, H Greenwood, V Spezi, S White, and N Frude. "Public Library Activity in the Areas of Health and Well-Being: Final Report." Edited by Museums Libraries and Archives Council. London, 2010. http://research.mla.gov.uk/evidence/viewpublication.php?dm=nrm\&pubid=1068.

Hodge, S, J Robinson, and P Davis. "Reading between the Lines: The Experiences of Taking Part in a Community Reading Project." Medical Humanities 33 (2007): 100-104. https://doi.org/10.1136/jmh.2006.000256.

Hornby, S, and B Glass, eds. Reader Development in Practice: Bringing Literature to Readers. London: Facet, 2008.

Hynes, J.C. "Library Work with Brain Damaged Patients: A New Mode of Bibliotherapy." Bulletin of the Medical Library Association 60, no. 2 (1972): 333-39.

Kitwood, T. Dementia Reconsidered: The Person Comes First. Buckingham: Open University Press, 1997.

Kvale, S, and S Brinkmann. InterViews: Learning the Craft of Qualitative Research Interviewing [2nd Edition]. London: Sage, 2009.

Longden, E, P Davis, J Billington, S Lampropoulou, G Farrington, F Magee, E Walsh, and R Corcoran. "Shared Reading: Assessing the Intrinsic Value of a Literature-Based Health Intervention." Medical Humanities, June 12, 2015, 1-8. https://doi.org/10.1136/medhum2015-010704.

McAllister, P, J Kerr, M McTear, M Mulvenna, R Bond, K Kirby, J Morning, and D Glover. 
"Towards Chatbots to Support Bibliotherapy Preparation and Delivery." In Chatbot Research and Design. CONVERSATIONS 2019. Lecture Notes in Computer Science, edited by Asbjørn Følstad, Theo Araujo, Symeon Papadopoulos, Effie Lai-Chong Law, OleChristoffer Granmo, Ewa Luger, and Petter Bae Brandtzaeg, 127-42. Cham: Springer International Publishing, 2020.

McLaine, S. "Bibliotherapy: Reading for Wellbeing in Old Age." In Alzheimer's Australia Dementia Forum. Melbourne, 2012. https://www.dementia.org.au/sites/default/files/Susan_McLaine.pdf.

McNicol, S. "Bibliotherapy and Graphic Medicine." In Bibliotherapy, edited by S McNicol and L Brewster. London: Facet, 2018.

McNicol, S, and L Brewster. Bibliotherapy. London: Facet Publishing, 2018.

Mead, N, and P Bower. "Patient-Centredness: A Conceptual Framework and Review of the Empirical Literature." Social Science \& Medicine (1982) 51, no. 7 (October 2000): 10871110. http://www.ncbi.nlm.nih.gov/pubmed/11005395.

Morral, K. "Well into Words: An Evaluation of the Kirklees Bibliotherapy Project," 2016. http://media.wix.com/ugd/6b65c6_f430a267c13848bdbe55ae13aa52ecdf.pdf.

Pink, S, and J Morgan. "Short-Term Ethnography: Intense Routes to Knowing." Symbolic Interaction 36, no. 3 (2013): 351-61. https://doi.org/10.1002/symb.66.

Rosenblatt, L M. Literature as Exploration. London: Heinemann, 1938.

Social Care Institute for Excellence. "Creative Arts for People with Dementia," 2015. https://www.scie.org.uk/dementia/living-with-dementia/keeping-active/creative-arts.asp.

The Health Foundation. "Person-Centred Care Made Simple What Everyone Should Know about Person-Centred Care," 2016.

Troscianko, E.T. "Fiction-Reading for Good or III: Eating Disorders, Interpretation and the Case for Creative Bibliotherapy Research." Medical Humanities 44 (2018): 201-11. 